\title{
Epidemiologic and economic analyses of pregnancy loss attributable to mastitis in primiparous Holstein cows
}

\author{
Mohammad O. Dahl, ${ }^{\dagger} \dagger$ Albert De Vries,‡ Fiona P. Maunsell, ${ }^{*}$ Klibs N. Galvao, ${ }^{\star} \S$ Carlos A. Risco, $\#$ \\ and Jorge A. Hernandez*1 \\ ${ }^{*}$ Department of Large Animal Clinical Sciences, College of Veterinary Medicine, University of Florida, Gainesville 32611-0910 \\ †Department of Medicine and Preventive Medicine, College of Veterinary Medicine, University of Mosul, Mosul, Iraq 41002 \\ łDepartment of Animal Sciences, University of Florida, Gainesville 32611-0910 \\ $\S \mathrm{D}$. H. Barron Reproductive and Perinatal Biology Research Program, University of Florida, Gainesville 32610 \\ \#Center for Veterinary Health Sciences, Oklahoma State University, Stillwater 74078-2005
}

\section{ABSTRACT}

The main objective of the study reported here was to examine the association between pregnancy loss (PL) and previous exposure to clinical or subclinical mastitis before breeding or during gestation in primiparous Holstein cows. A secondary objective was to estimate the cost of clinical mastitis during gestation, including that of PL attributable to mastitis in study cows. A total of 687 primiparous Holstein cows from 1 dairy farm were included in a matched case-control study. Study cows were declared pregnant via ultrasound on d 33 after timed artificial insemination (TAI). Case cows $(\mathrm{n}=78)$ were those diagnosed as nonpregnant by rectal palpation on d 47 or 75 after TAI. Control cows were those confirmed as pregnant by rectal palpation on $\mathrm{d} 47$ and 75 after TAI. Case cows were matched with eligible controls according to year of calving and calving-toconception interval $\pm 3 \mathrm{~d}$. Cows were assigned to 1 of 3 groups: (1) cows not affected with clinical or subclinical mastitis; (2) cows affected with subclinical mastitis (Dairy Herd Improvement Association somatic cell score $>4.5$ ); and (3) cows affected with clinical mastitis during 2 exposure periods, 1 to $42 \mathrm{~d}$ before breeding or during gestation (1 to PL diagnosis day for case cows, and 1 to $75 \mathrm{~d}$ for control cows). Conditional logistic regression was used to model the odds of PL as a function of previous exposure to mastitis in study cows. Mastitis before breeding was not associated with PL. The odds of PL were 2.21 times greater in cows affected with clinical mastitis during gestation (95\% confidence interval $=1.01,4.83)$, compared with cows without mastitis, after controlling for breeding type and lameness. The cost of clinical mastitis during gestation was $\$ 149$, which includes the cost (\$27) of PL attributable to mastitis. In conclusion, this study provides evidence

Received February 21, 2018.

Accepted July 2, 2018.

${ }^{1}$ Corresponding author: hernandezja@ufl.edu that clinical mastitis during gestation can cause PL in primiparous dairy cows leading to economic losses.

Key words: pregnancy loss, mastitis, embryo transfer, lameness, primiparous cows

\section{INTRODUCTION}

Pregnancy loss (PL) and mastitis are important health issues that affect dairy farms' profitability. Pregnancy loss is the loss of pregnancy in cows that were first confirmed pregnant at about 30 to $50 \mathrm{~d}$ after AI and later exhibited visual signs of abortion or were declared not pregnant during reconfirmation of pregnancy (Risco et al., 1999; Chebel et al., 2004; Moore et al., 2005). In the United States, the prevalence of PL has varied between 6 to $39 \%$ in dairy cows (Risco et al., 1999; Chebel et al., 2004; Moore et al., 2005). The average economic loss due to PL in dairy cows has been estimated at $\$ 555$ per case (De Vries, 2006). Mastitis is the most frequently occurring disease in dairy cows (NAHMS, 2007). The average economic loss per case of clinical mastitis has been estimated at $\$ 155$ (Cha et al., 2011) and $\$ 179$ (Bar et al., 2008).

Pregnancy loss has been linked to clinical mastitis as a consequence of endotoxins or inflammatory responses on follicular growth, embryo development, or corpus luteum (CL) survival. Inducing clinical mastitis with Escherichia coli or Streptococcus uberis in dairy cows increased the concentration of $\mathrm{PGF}_{2 \alpha}$ in blood (Cullor, 1990; Hockett et al., 2000) and proinflammatory cytokines in milk, lymph, and blood (Shuster et al., 1993; Persson Waller et al., 2003; Rambeaud et al., 2003). Cytokines (particularly IFN- $\gamma$, tumor necrosis factor- $\alpha$, and IL-1 $\beta$ ) and $\mathrm{PGF}_{2 \alpha}$ can cause luteolysis and, subsequently, termination of pregnancy in dairy cows (Pate, 1994). Further, in vitro, embryo growth is affected when LPS or $\mathrm{PGF}_{2 \alpha}$ are added to oocyte maturation medium (Soto et al., 2003).

Although several observational studies have investigated the relationship between exposure to mastitis and 
subsequent PL in dairy cows, a recent systematic review revealed that only 2 studies have produced strong evidence that mastitis can be a predisposing factor for PL (Dahl et al., 2017). In one study, cows affected with clinical mastitis during the first $45 \mathrm{~d}$ of gestation were 2.7 times at higher risk of PL within the following $90 \mathrm{~d}$ after diagnosis of mastitis, compared with cows without mastitis (Risco et al., 1999). In that study, however, exposure to clinical mastitis before breeding and exposure to subclinical mastitis before breeding or during gestation were not investigated. In another study, Moore et al. (2005) examined the relationship between subclinical mastitis (and other exposure factors) and PL detected via ultrasound on d 27 to 28 or rectal palpation on d 35 to 41 after AI in dairy cows. In that study, the odds of PL on d 35 to 41 were 3.6 times higher in cows with SCS $>4.5$ at the DHIA test during the $30 \mathrm{~d}$ before AI. Whereas other observational studies have examined the relationship between mastitis and PL in dairy cows, study results were inconclusive because the temporal relationship between mastitis and PL was not well-established (Dahl et al., 2017).

Economic losses due to the association between mastitis and subsequent PL have not been investigated. For example, the average cost of clinical mastitis $(\$ 155$ and $\$ 179$ ) estimated by Cha et al. (2011) and Bar et al. (2008), respectively, did not include risk of subsequent PL. Thus, the costs of mastitis have been underestimated. The main objective of the study reported here was to examine the association between PL and previous exposure to clinical or subclinical mastitis before breeding or during gestation in primiparous Holstein cows. A secondary objective was to estimate the cost of clinical mastitis during gestation, including that of PL attributable to mastitis in study cows.

\section{MATERIALS AND METHODS}

\section{Study Herd}

Holstein cows from the University of Florida Dairy Unit, located in Gainesville, were used in this study. This herd consisted of approximately 500 lactating Holstein cows housed in freestall barns provided with sand bedding under a common roof. Cows were milked twice daily using a modern double-12 herringbone rapid-exit milking parlor equipped with automatic identification and milk recording, where milk yield at each milking was recorded using milk meters (AfiFlo, S.A.E. Afikim, Kibbutz Afikim, Israel). Cows were subjected to a timed artificial insemination (TAI) reproduction management program. Briefly, cows were presynchronized at 38 to $44 \mathrm{DIM}$ with 2 injections of $\mathrm{PGF}_{2 \alpha}$, given 14 $\mathrm{d}$ apart. Twelve days after the second $\mathrm{PGF}_{2 \alpha}$ injection, cows were enrolled in an Ovsynch 56 program (d 0, GnRH; 7 d later, $\mathrm{PGF}_{2 \alpha} ; 56 \mathrm{~h}$ after $\mathrm{PGF}_{2 \alpha}$ injection, second dose of $\mathrm{GnRH}$; and $16 \mathrm{~h}$ after second dose of GnRH cows were TAI). In addition, timed embryo transfer (ET) using 7-d-old in vitro-produced embryos was used for breeding, particularly during summer months to improve fertility in heat-stressed cows (Hansen, 2002). Pregnancy diagnosis was based on detection of embryo heartbeat via transrectal ultrasonography on d 33 after TAI; cows classified as not pregnant were enrolled in the Ovsynch 56 program again. Pregnancy was later confirmed based on detection of embryonic vesicles by rectal palpation on d 47 and 75 after TAI. Postpartum health monitoring included evaluation of cows on $\mathrm{d} 4,7$, and 12 postcalving. Production, reproductive services, health events, and treatment were entered on a daily basis into the AfiFarm dairy records system (S.A.E. Afikim).

\section{Study Cows}

Nine hundred ninety-one primiparous Holstein cows that calved between May 2006 and October 2013, bred later, and declared pregnant by ultrasound examination on d 33 were considered for inclusion. One hundred eighty-seven cows with a calving-to-conception interval (CCI) greater than $175 \mathrm{~d}$ were excluded because the risk of PL was low (Risco et al., 1999). Cows with incomplete health events records or culled before d 75 after TAI, which was the day for the second pregnancy reconfirmation, were also excluded. The final study sample was 687 primiparous Holstein cows declared pregnant on d 33 after TAI. The study targeted primiparous cows because the burden of mastitis is different between primiparous and multiparous cows (Hertl et al., 2011) and the effect of mastitis and other exposure factors on PL in primiparous cows is not known.

\section{Study Design}

This investigation was designed as a matched case control study. Case cows $(\mathrm{n}=78)$ were those declared pregnant via ultrasound on d 33 after TAI and later diagnosed as nonpregnant by rectal palpation on d 47 or 75 after TAI. Control cows were those confirmed as pregnant by rectal palpation on d 47 and 75 after TAI. Control cows were matched to case cows ( 1 to 28 control cows per case cow, average $=8$ ) based on year of calving and CCI $\pm 3 \mathrm{~d}$.

\section{Diagnosis of Mastitis}

In our study, cows affected with clinical mastitis were those with visible changes in milk detected during milk- 
ing procedures by designated farm personnel trained by the attending veterinarian (with or without an inflamed mammary gland or systemic signs of illness) and treated using a standardized farm protocol prepared by the farm's attending veterinarian. Cows affected with subclinical mastitis were those with SCS >4.5 (Smith, 1996) based on the monthly DHIA reports. Initially, cows were assigned to 1 of 3 groups: (1) cows with no evidence of subclinical or clinical mastitis; (2) cows with evidence of subclinical mastitis (SCS $>4.5$ in at least one DHIA test day); and (3) cows with evidence of clinical mastitis (with or without evidence of subclinical mastitis). In addition, 2 exposure periods were considered: (1) 1 to $42 \mathrm{~d}$ before breeding, to target the required period for antral follicle development until ovulation (Mayes, 2002); and (2) 1 to $75 \mathrm{~d}$ of gestation, when the second pregnancy confirmation was performed in study herd ( 1 to PL diagnosis day for case cows, and 1 to $75 \mathrm{~d}$ for control cows). Finally, 1 case cow diagnosed with subclinical mastitis between $\mathrm{d}$ 33 and 75 of gestation was excluded because exposure to mastitis before PL was not certain (i.e., to avoid misclassification bias).

\section{Data Collection}

We collected data for each study cow from herd records on cow identification, calving date, calving season (heat stress: yes, no), dystocia (yes, no), retained fetal membranes (yes, no), metritis (yes, no), ketosis (yes, no), lameness (yes, no), breeding date, breeding season (heat stress: yes, no), breeding type (AI, ET), breeding service number $(1,2,3,4)$, and milk yield (low, medium, and high). Data were from 2 periods: (1) 1 to $42 \mathrm{~d}$ before breeding and (2) 1 to $75 \mathrm{~d}$ of gestation.

In our study, cows with dystocia were those that experienced calving difficulty and required assistance during parturition. Cows affected with retained fetal membranes were those observed with retention of fetal membranes $>24 \mathrm{~h}$ after delivery. Cows with metritis had a postpartum large uterus over the pelvic brim plus a fetid uterine discharge with or without systemic signs of illness. Cows with ketosis had ketone bodies detected on urine ketone analysis. Both metritis and ketosis were mostly detected (65-75\%) between d 7 and 14 postpartum. Cows affected with lameness were those with an arched back when standing and walking, displayed an abnormal gait and favored one or more legs when walking, and were affected with and treated for digital dermatitis $(\mathrm{n}=8)$, white line disease $(\mathrm{n}=4)$, hoof ulcer $(\mathrm{n}=3)$, hoof abscess $(\mathrm{n}=1)$, foot problem $(\mathrm{n}=$ $6)$, hoof wart $(\mathrm{n}=3)$, leg injury $(\mathrm{n}=1)$, swollen leg $(\mathrm{n}=1)$, and lameness from other causes $(\mathrm{n}=9)$. Heat stress represented the period when consecutive daily temperature-humidity index (THI) was $\geq 72$ (Armstrong, 1994). Data for daily averages of temperature $\left({ }^{\circ} \mathrm{F}\right)$ and humidity (\%) in Gainesville, Florida, from January 2007 to December 2013 were obtained from Weather Underground (https://www.wunderground .com/history/). Daily THI was calculated as THI = temperature $-[0.55-(0.55 \times$ relative humidity $)] \times$ (temperature - 58) (Kelly and Bond, 1971). In the present study, heat stress periods were June 8 to October 10, 2007; May 7 to Octover 16, 2008; May 5 to October 16, 2009; May 1 to October 2, 2010; April 19 to October 13, 2011; April 29 to October 8, 2012; and May 18 to October 8, 2013. Average daily milk yield from 5 to 60 DIM for each cow was obtained from the herd records. Milk yield per cow per day was defined as low $(<24.36 \mathrm{~kg})$, medium $(24.36$ to $30.78 \mathrm{~kg}$ ), and high $(>30.78 \mathrm{~kg})$ based on the frequency of distribution (first, second and third, and fourth quartiles, respectively). Milkings missing from daily milk yield data were predicted as previously described (Quist et al., 2007). Milk yield data for 84 cows were not included in the analysis because data for 75 cows were not available during the investigated period (5 to 60 DIM) or could not be predicted for 9 cows due to missing at least 7 successive days of milk yield data at the beginning or end of the investigated period.

\section{Epidemiologic Analysis}

In our study, a sample size of 70 case cows and an average of 7 to 8 control cows (matched to cases based on their CCI) was sufficient to declare an odds ratio of 2.2 as statistically significant, assuming exposure to clinical mastitis among control cows was $8 \%$.

Conditional logistic regression was used to model the odds of PL as a function of previous exposure to mastitis before breeding or during gestation. In this analysis, the variable selection method was used as a modelbuilding strategy (Hosmer and Lemeshow, 2000). Initial screening of mastitis and other investigated exposure factors associated with PL was performed by use of univariable conditional logistic regression. Variables with a value of $P \leq 0.20$ were considered for the multivariable analysis. Association between variables was examined (i.e., those with $P \leq 0.20$ ), and when a pair of variables was associated by use of a chi-squared test (2 tailed) the exposure variable judged as most biologically plausible was further examined in the analysis. In the multivariable analysis, a manual forward selection technique was used by adding one variable at a time and assessing the model goodness-of-fit using the likelihood ratio test statistic. In that process, the variable with the lowest $P$-value was added first. Two main models were constructed to examine the relationship between PL and 
exposure to mastitis before breeding or during gestation in study cows. In each model, the variable for mastitis was the main exposure of interest. Two-way interaction terms between mastitis and other exposure factors were not examined because the number of case cows exposed to mastitis was low. Exposure factors retained in final models were examined for confounding by adding each of the variables to the model, and assessing changes in odds ratios ( $\mathbf{O R}$; i.e., $\geq 20 \%$ ) of the remaining variables in the model.

The fit of the final models to the data were assessed by a visual examination of residual plots (standardized $\Delta \beta$ values vs. observation number and $\Delta \beta$ vs. fitted values; Hosmer and Lemeshow, 2000). The ability of the models to discriminate between cows with or without PL was determined using the receiver operating characteristic (ROC) curve (Hosmer and Lemeshow, 2000). In the final models, variables with a value of $P \leq 0.05$ (2-tailed) were considered significant, and the adjusted OR and $95 \%$ confidence interval were reported. The attributable risk (AR) of PL due to mastitis among cows exposed to mastitis was determined from the OR using the equation: $\mathrm{AR}=(\mathrm{OR}-1) / \mathrm{OR}$ (Kuritz and Landis, 1987). Statistical analyses were performed using STATA 13.0 (StataCorp, College Station, TX) and SAS 9.4 (SAS Institute Inc., Cary, NC).

\section{Economic Analysis}

In this analysis, cost of mastitis was limited to costs of treatment, milk loss, and PL attributable to exposure to clinical mastitis between $\mathrm{d} 1$ and 75 of gestation. Economic consequences of mastitis after $d$ 75 of gestation were not included in the analysis because epidemiologic investigation was limited to d 75 of gestation. Milk price was set at $\$ 0.42$ per kilogram (average milk prices for 2017; http://dairy.aae.wisc.edu/ dairy-marketing-tools/, accessed Sep. 10, 2017). Cost of treatment of clinical mastitis was set at $\$ 55.50$ per case (adjusted value for inflation; $\$ 1$ in July 2008 was $\$ 1.11$ in July 2017; https://data.bls.gov/cgi-bin/cpicalc .pl; Bar et al., 2008). Cost of milk loss was estimated as $\$ 66.22$ per case based on the average of milk loss during $50 \mathrm{~d}$ following clinical mastitis in primiparous cows of $157.67 \mathrm{~kg}$ (Schukken et al., 2009).

Cost of PL in study cows was estimated as $\$ 274$ per case. In brief, the calculation included (1) quadratic function fitted from costs of PL estimated by De Vries (2006) for primiparous cows that had a relative milk yield 100\%; (2) average of CCI in study cows of 94 d; and (3) PL occurring in study cows at an average of $60 \mathrm{~d}$ of gestation. This cost was then multiplied by 1.21 to adjust for inflation ( $\$ 1$ in May 2006 was $\$ 1.21$ in May 2017; https://data.bls.gov/cgi-bin/cpicalc.pl).
Cost of PL attributable to clinical mastitis among cows affected with clinical mastitis was estimated considering the AR that was previously calculated in this study. Therefore, cost of PL attributable to clinical mastitis $(\$ /$ case) was $[\mathrm{AR} \times \%$ cows with clinical mastitis that observed PL $\times$ cost of PL $(\$ /$ case of PL)]. Consequently, the cost of clinical mastitis (\$/case) was calculated as $[$ cost of treatment $(\$ /$ case $)+$ cost of milk loss $(\$ /$ case $)+$ cost of $\mathrm{PL}$ attributable to clinical mastitis $(\$ /$ case)]. Finally, a sensitivity analysis was performed by adjusting $( \pm 20 \%)$ the input values for costs of clinical mastitis treatment, milk price, or PL.

\section{RESULTS}

\section{Epidemiologic Analysis}

One hundred nineteen of 991 (12\%) cows experienced PL between d 33 and 75 of gestation; 232 (23\%) cows were diagnosed with clinical mastitis. Median CCI in study cows was $79 \mathrm{~d}$ (1st quartile $=77$, 3rd quartile $=117)$. In the univariable analysis, the variable for mastitis before breeding was not associated with PL $(P \geq 0.31$; Table 1$)$. The variables for mastitis during gestation, lameness before breeding, ketosis, and breeding type (ET) had a value of $P \leq 0.20$ (Table 1 ).

Pregnancy Loss as a Function of Exposure to Mastitis Before Breeding. In the multivariable analysis, the variables for mastitis and breeding type were retained in the final model. Pregnancy loss was not associated with mastitis before breeding $(P \geq$ 0.37 ), after controlling for breeding type (OR in cows with subclinical mastitis $=1.44 ; 95 \% \mathrm{CI}=0.63,3.29$; $P=0.37)$. Pregnancy loss was associated with breeding type (ET; OR $=2.08 ; 95 \% \mathrm{CI}=1.09,3.97$ ) after controlling for mastitis. The effect of ET on PL was not confounded by mastitis before breeding (e.g., adjusted OR changed 4\%). A visual examination of residuals for the model did not reveal existence of influential observations; that is, $\Delta \beta$ values for the variables of mastitis or breeding type were not extreme (i.e., not $>1$ ), which supported overall goodness-of-fit. Finally, the area under the ROC curve was $0.71(95 \% \mathrm{CI}=0.64,0.77)$, indicating a moderate predictive ability for the model.

Pregnancy Loss as a Function of Exposure to Mastitis During Gestation. In the multivariable analysis, the variables for mastitis during gestation, breeding type, and lameness before breeding were retained in the final model (Table 2). The odds of PL were 2.2 times higher in cows affected with clinical mastitis $(\mathrm{OR}=2.21 ; 95 \% \mathrm{CI}=1.01,4.83)$, compared with cows without mastitis, after controlling for breeding type and lameness. The effect of clinical mastitis on PL was not confounded by breeding type or lameness. 
Table 1. Univariable conditional logistic regression analysis for the odds of pregnancy loss as a function of mastitis and other exposure factors in primiparous Holstein cows ${ }^{1}$

\begin{tabular}{|c|c|c|c|c|c|}
\hline \multirow[b]{2}{*}{ Variable } & \multicolumn{2}{|c|}{ Pregnancy loss } & \multirow[b]{2}{*}{ OR } & \multirow[b]{2}{*}{$95 \% \mathrm{CI}$} & \multirow[b]{2}{*}{$P$-value } \\
\hline & Yes & No & & & \\
\hline \multicolumn{6}{|l|}{ Mastitis before breeding } \\
\hline No mastitis & 66 & 499 & 1.00 & Referent & NA \\
\hline Subclinical mastitis & 8 & 46 & 1.51 & $0.67,3.40$ & 0.31 \\
\hline Clinical mastitis & 3 & 31 & 0.62 & $0.17,2.28$ & 0.48 \\
\hline \multicolumn{6}{|l|}{ Mastitis during gestation } \\
\hline No mastitis & 60 & 486 & 1.00 & Referent & NA \\
\hline Subclinical mastitis & 4 & 48 & 0.67 & $0.22,2.03$ & 0.48 \\
\hline Clinical mastitis & 10 & 45 & 2.22 & $1.03,4.79$ & 0.04 \\
\hline \multicolumn{6}{|l|}{ Lameness before breeding } \\
\hline No & 74 & 599 & 1.00 & Referent & NA \\
\hline Yes & 4 & 10 & 3.45 & $0.99,12.00$ & 0.05 \\
\hline \multicolumn{6}{|l|}{ Lameness during gestation } \\
\hline No & 76 & 589 & 1.00 & Referent & NA \\
\hline Yes & 2 & 20 & 0.64 & $0.14,2.93$ & 0.57 \\
\hline \multicolumn{6}{|l|}{ Dystocia } \\
\hline No & 72 & 569 & 1.00 & Referent & NA \\
\hline Yes & 6 & 40 & 1.13 & $0.45,2.82$ & 0.78 \\
\hline \multicolumn{6}{|l|}{ Retained fetal membranes } \\
\hline No & 78 & 606 & 1.00 & Referent & NA \\
\hline Yes & 0 & 3 & ND & ND & ND \\
\hline \multicolumn{6}{|l|}{ Metritis } \\
\hline No & 52 & 422 & 1.00 & Referent & NA \\
\hline Yes & 26 & 187 & 1.01 & $0.60,1.69$ & 0.96 \\
\hline \multicolumn{6}{|l|}{ Ketosis } \\
\hline No & 55 & 358 & 1.00 & Referent & NA \\
\hline Yes & 23 & 251 & 0.61 & $0.36,1.03$ & 0.06 \\
\hline \multicolumn{6}{|l|}{ Calving season (heat stress) } \\
\hline No & 37 & 271 & 1.00 & Referent & NA \\
\hline Yes & 41 & 338 & 0.93 & $0.56,1.53$ & 0.79 \\
\hline \multicolumn{6}{|l|}{ Breeding season (heat stress) } \\
\hline No & 38 & 332 & 1.00 & Referent & NA \\
\hline Yes & 40 & 277 & 1.34 & $0.81,2.20$ & 0.24 \\
\hline \multicolumn{6}{|l|}{ Breeding type } \\
\hline AI & 54 & 491 & 1.00 & Referent & NA \\
\hline Embryo transfer & 24 & 118 & 2.00 & $1.07,3.71$ & 0.02 \\
\hline \multicolumn{6}{|l|}{ Breeding service number } \\
\hline First & 49 & 431 & 1.00 & Referent & NA \\
\hline Second & 19 & 137 & 1.46 & $0.21,9.91$ & 0.69 \\
\hline$\geq$ Third & 10 & 41 & 1.54 & $0.16,14.54$ & 0.70 \\
\hline \multicolumn{6}{|l|}{ Milk yield } \\
\hline Low $(<24.36 \mathrm{~kg} / \mathrm{d})$ & 18 & 133 & 1.00 & $0.52,1.91$ & 0.98 \\
\hline Medium $(24.36$ to $30.78 \mathrm{~kg} / \mathrm{d})$ & 33 & 268 & 1.00 & Referent & NA \\
\hline High $(>30.78 \mathrm{~kg} / \mathrm{d})$ & 15 & 136 & 0.97 & $0.51,1.85$ & 0.94 \\
\hline
\end{tabular}

${ }^{1} \mathrm{OR}=$ odds ratio; $\mathrm{NA}=$ not applicable $\mathrm{ND}=$ not determined.

In that model, PL was associated with breeding type (ET) and lameness. The effect of ET on PL was not confounded by mastitis or lameness. Similarly, the effect of lameness on PL was not confounded by mastitis or breeding type. A visual examination of residuals for the final model did not reveal existence of influential observations. The area under the ROC curve was 0.73 $(95 \% \mathrm{CI}=0.67,0.79)$, indicating a moderate predictive ability for the model. Finally, attributable proportion analysis indicated that PL in cows affected with clinical mastitis during gestation could have been reduced by $54 \%$ if clinical mastitis had been prevented.

\section{Economic Analysis}

The cost of clinical mastitis occurring during the first 75 d of gestation was $\$ 148.99$ per case (Table 3). The cost of PL attributable to clinical mastitis was $\$ 27.27$ per case. Finally, the cost of clinical mastitis varied from $\$ 135$ to $\$ 160$ if the milk price, costs of clinical mastitis treatment, or PL varied by $\pm 20 \%$ (Table 4 ).

\section{DISCUSSION}

Study results revealed that clinical mastitis during gestation, breeding type (ET), and lameness before 
Table 2. Final multivariable conditional logistic regression analysis for the odds of pregnancy loss as a function of mastitis during gestation in primiparous Holstein cows

\begin{tabular}{|c|c|c|c|}
\hline Variable & $\mathrm{OR}^{1}$ & $95 \% \mathrm{CI}$ & $P$-value \\
\hline \multicolumn{4}{|c|}{ Mastitis during gestation } \\
\hline No mastitis & - & - & - \\
\hline Subclinical mastitis & 0.65 & $0.21,2.00$ & 0.45 \\
\hline Clinical mastitis & 2.21 & $1.01,4.83$ & 0.04 \\
\hline \multicolumn{4}{|l|}{ Breeding type } \\
\hline $\mathrm{AI}$ & - & - & - \\
\hline Embryo transfer & 2.04 & $1.07,3.86$ & 0.02 \\
\hline \multicolumn{4}{|c|}{ Lameness before breeding } \\
\hline No & - & - & - \\
\hline Yes & 4.13 & $1.18,14.41$ & 0.02 \\
\hline
\end{tabular}

breeding were predisposing factors for PL in study cows. A case-control study design enabled us to investigate the association between PL and previous exposure to mastitis in 2 different exposure risk periods: before breeding (the period for antral follicle development until ovulation) and during gestation (the period for embryonic and early fetal development). Potential confounding effects on PL were reduced by targeting primiparous cows, matching control cows to case cows (on the basis of year of calving and CCI $\pm 3 \mathrm{~d}$ ), and statistically controlling for other exposure factors that can potentially affect PL in dairy cows. In our study, the cost of clinical mastitis during gestation was $\$ 149$, which includes the cost $(\$ 27)$ of PL attributable to mastitis.

\section{Epidemiologic Analysis}

Pregnancy Loss as a Function of Exposure to Mastitis Before Breeding. The odds of PL were 1.4 times higher in cows affected with subclinical mastitis compared with cows without mastitis after controlling for breeding type; however, this association was not significant. One explanation is that subclinical mastitis does not trigger a systemic inflammatory response enough to affect follicular growth and oocyte quality, as observed in vitro by Soto et al. (2003). Another expla- nation can be that the association between subclinical mastitis and PL is real, but the number of case cows affected with subclinical mastitis was too small to declare the observed association statistically significant (i.e., observed power $=0.70$ ). Our study results differ from those by Moore et al. (2005), where cows affected with subclinical mastitis (DHIA SCS >4.5) within $30 \mathrm{~d}$ before TAI were 3.6 times at higher risk of PL between d 28 to 35 or 41 of pregnancy, compared with cows with DHIA SCS $\leq 4.5$. On d 28, cows were examined for pregnancy via location of the fetus and heartbeat by use of diagnostic ultrasonography. An explanation for the observed association between subclinical mastitis before breeding and PL was not offered. If subclinical mastitis before breeding can trigger a systemic inflammatory response enough to cause PL, then, in our study, it is possible that several study cows could have experienced PL 28 to $32 \mathrm{~d}$ after TAI and were classified as nonpregnant on d 33 after TAI.

In this study, PL was not associated with clinical mastitis before breeding. One explanation is that the number of case cows affected with clinical mastitis within $42 \mathrm{~d}$ before breeding was too small $(\mathrm{n}=3)$. In another study (Hernandez et al., 2012), clinical mastitis during early lactation in combination with low body condition (BCS $\leq 2.75$ ) at 70 DIM increased the risk of PL in dairy cows. Hernandez et al. (2012) explained that events of clinical mastitis during the first 10 to 50 DIM can induce a prolonged negative energy balance in cows leading to losses of BW and BCS days before or after insemination. Low BCS is a known predisposing factor for embryonic loss. In that study, the interaction effect between clinical mastitis and low BCS, if present, was considered weak. In our study, we did not examine the interaction between mastitis before breeding and body condition, because the number of case cows affected with mastitis was low and because BCS data were missing in most study cows. The finding by Hernandez et al. (2012) that mastitis in combination with loss of body condition can lead to PL in dairy cows, needs further investigation.

Table 3. Costs of clinical mastitis ( 1 to maximum $75 \mathrm{~d}$ of gestation) and pregnancy loss (PL; $\$ /$ case) in primiparous Holstein cows

\begin{tabular}{lc}
\hline Model parameter & Cost (\$/case) \\
\hline Cost of clinical mastitis ${ }^{1}$ & 148.99 \\
Cost of clinical mastitis treatment & 55.5 \\
Cost of milk loss $(157.67 \mathrm{~kg} \times \$ 0.42)^{2}$ & 66.22 \\
Cost of PL attributable to clinical mastitis $(0.5475 \times 0.1818 \times \$ 274)^{3}$ & 27.27 \\
\hline${ }^{1}$ This cost is based on costs of clinical mastitis treatment, milk loss, and PL attributable to mastitis. \\
${ }^{2}$ Represents average of milk loss during $50 \mathrm{~d}$ following clinical mastitis $\times$ milk price. \\
${ }^{3}$ Represents attributable risk $\times \%$ cows with clinical mastitis that observed PL $\times$ cost of PL in primiparous \\
cows.
\end{tabular}


Table 4. Effect of changes in input parameter on the total cost of clinical mastitis in primiparous Holstein cows

\begin{tabular}{lc}
\hline Model parameter & $\begin{array}{c}\text { Cost of clinical } \\
\text { mastitis }^{1}(\$ / \text { case })\end{array}$ \\
\hline Average case & 148.99 \\
Milk price & 162.23 \\
$\quad+20 \%$ & 135.74 \\
$\quad-20 \%$ & \\
Cost of clinical mastitis treatment & 160.09 \\
$\quad+20 \%$ & 137.89 \\
$\quad-20 \%$ & 154.44 \\
Cost of pregnancy loss (PL) & 143.53 \\
\hline $20 \%$ & \\
\hline
\end{tabular}

${ }^{1}$ This cost is based on costs of clinical mastitis treatment, milk loss, and PL attributable to mastitis.

Pregnancy Loss as a Function of Exposure to Mastitis During Gestation. Pregnancy loss was associated with exposure to clinical mastitis during gestation in study cows. We offer several explanations for this observed association. First, early embryonic stages are sensitive to inflammatory responses. In rats, blastocysts have a receptor for tumor necrosis factor- $\alpha$ (Pampfer, 2001), which can cause apoptosis to embryo blastomeres, leading to a reduction of inner cell mass number, and affect embryo development (Hansen et al., 2004). In addition, in vitro embryo development in cows has been affected by adding nitric oxide (NO) to maturation medium after fertilization (Soto et al., 2003). Affected embryos might produce enough IFN- $\tau$ for maternal recognition of the pregnancy, but not enough to prepare favorable uterine environment for receiving the conceptus. That is, IFN- $\tau$ induces IFNstimulated gene expression in the endometrium that is important for embryo elongation and implantation (Brooks et al., 2014). Another possible pathway is that pregnancy survival is compromised by effect of $\mathrm{PGF}_{2 \alpha}$ on CL, causing luteolysis and termination of the pregnancy (Pate, 1994). This effect could be greater during late embryonic and early fetal development stages; that is, between d 24 and 42 to 50, and later than d 50 of gestation, respectively (Santos et al., 2004), because there is evidence that CL tissues from luteal phase is different from that for pregnant phase in the protein expression level (Chung et al., 2012). Our study results support those reported by Risco et al. (1999), where cows affected with clinical mastitis during the first 45 $\mathrm{d}$ of gestation were 2.7 times as likely to experience PL within the following $90 \mathrm{~d}$ after diagnosis of mastitis compared with cows not affected with clinical mastitis.

Follow-up Period for Pregnancy Loss. In our study, the risk period for PL (33 to $75 \mathrm{~d}$ after TAI) was different compared with those by Risco et al. (1999) and Moore et al. (2005). In our study, the risk period for PL was justified based on the study farms' reproduction management program, which included rectal palpation of study cows to confirm pregnancy on d 47 and 75 after TAI. In Risco et al. (1999), the risk period for PL was 1 to $135 \mathrm{~d}$ after TAI ( $90 \mathrm{~d}$ after cows were diagnosed with clinical mastitis during the $45 \mathrm{~d}$ of gestation). If 1 or more cows experienced PL 80 to $90 \mathrm{~d}$ after exposure to mastitis, it is possible that the risk of PL attributable to clinical mastitis was overestimated, as the lifespan of proinflammatory cytokines produced in response to mastitis pathogens is 5 to $6 \mathrm{~d}$ (Rambeaud et al., 2003). In Moore et al. (2005), the risk period for PL was $41 \mathrm{~d}$ after TAI (cows were diagnosed with subclinical mastitis 1 to $30 \mathrm{~d}$ before $\mathrm{AI}$ ). In that study it is possible that the estimated risk of PL attributable to subclinical mastitis could have been higher if study cows had been followed-up longer. Further observational prospective studies can measure duration of subclinical or clinical mastitis to better establish the temporal relationship between exposure to mastitis and PL in dairy cows.

Pregnancy Loss and Breeding Type. In our study, PL was associated with breeding type (ET) after controlling for mastitis and lameness. Because embryos used in study cows were produced in vitro, the quality of embryos could have been affected by the environment of culture medium (Rizos et al., 2008) or during the handling and freezing processes. Eventually, IFN- $\tau$ secretion from embryos was compromised, affecting pregnancy maintenance. Another possible explanation is that embryo survival post-transfer might have been compromised by an altered uterine environment due to pulsatile release of $\mathrm{PGF}_{2 \alpha}$ as a result of manipulation of the uterus during the transfer process (Scenna et al., 2005). Our study results support the conclusion reached by Block et al. (2010), that risk of PL in cows diagnosed pregnant $32 \mathrm{~d}$ after breeding is higher in cows bred with in vitro-produced embryos compared with cows bred via AI. The use of fresh embryos for ET was also associated with PL in lactating Holstein cows declared pregnant on d 28 after breeding compared with cows bred via AI (Demetrio et al., 2007).

Pregnancy Loss and Lameness. In our study, PL was associated with lameness 1 to $42 \mathrm{~d}$ before breeding, after controlling for mastitis and breeding type. The effect of lameness on PL was not confounded by mastitis or breeding type. In our study, cows classified as lame were those with severe lameness. The risk of misclassification of this group of cows is considered low, although cows affected with moderate lameness (e.g., gait is not normal, but cow does not favor 1 or more legs when walking) could have been misclassified as nonlame. We offer 2 explanations for the observed association between lameness and PL. Cows affected with lameness experience hyperalgesia (increased sensitivity to pain), 
which can persist for $\geq 28$ d (Whay et al., 1998; Whay et al., 2005). Pain associated with lameness can alter feeding behavior in affected cows (Thorup et al., 2016), decrease feed intake (Shonka and Spurlock, 2014), a subsequent decrease in body condition (Gráff et al., 2016), and a prolonged state of negative energy balance that can affect follicular growth, oocyte quality, and embryo survival (Santos and Ribeiro, 2014). Another explanation is that lameness can stimulate a systemic inflammatory response, including an increased gene expression for proinflammatory cytokines (O'Driscoll et al., 2015), which can affect follicular growth and oocyte quality. The association between lameness and PL in dairy cows was reported to improve reproduction in dairy cows in a review paper on nutrition and physiology (Santos et al., 2010). In that report, the odds of PL were 2.6 times higher in cows affected with lameness during first 60 DIM compared with cows without lameness; however, sampling methods and procedures to assess potential confounding effects of other exposure factors on PL in study cows were not reported.

\section{Economic Analysis}

The estimated cost of clinical mastitis occurring during the first $75 \mathrm{~d}$ of gestation was $\$ 149$ (including $\$ 27$ or $22 \%$ due to PL attributable to clinical mastitis). In our study, the estimated cost of clinical mastitis was based on costs of clinical mastitis treatment, milk loss, and PL due to clinical mastitis. To our knowledge, no other studies have estimated the cost of clinical mastitis due to PL attributable to mastitis. Previous studies estimated the cost of mastitis in dairy cows at $\$ 179$ (Bar et al., 2008) or $\$ 155$ (Cha et al., 2011). In these 2 studies, however, methods used to estimate the cost of mastitis were different (e.g., the estimated cost of mastitis included primiparous and multiparous cows and the cost of mortality).

This study had several limitations. First, the study was conducted on a single herd; thus, caution should be applied when extrapolating these results to other herds or situations. Second, the number of case cows exposed to mastitis before breeding or during gestation was low, a situation that prevented us from examining interaction effects between mastitis and other exposure factors on PL. Third, the diagnosis of subclinical mastitis was based on monthly DHIA reports (an inherent limitation in observational, retrospective studies); thus, it is possible that cows with high SCC on days other than DHIA test-day were not detected. Fourth, we did not examine the relationship between BCS and PL because herd records had incomplete BCS data. The relationship between body condition alone or in combination with exposure to mastitis needs further research. Fi- nally, the observed effect of lameness before breeding on PL in study cows is inconclusive, as the number of case cows affected with lameness was small.

\section{CONCLUSIONS}

Mastitis before breeding was not associated with PL. Clinical mastitis during gestation was a predisposing factor for PL in study cows. In addition, ET or lameness before breeding can be predisposing factors for PL. The cost of clinical mastitis during gestation was $\$ 149$, which includes the cost $(\$ 27)$ of PL attributable to mastitis.

\section{ACKNOWLEDGMENTS}

This project was funded in part by the University of Florida's College of Veterinary Medicine and Department of Animal Sciences.

\section{REFERENCES}

Armstrong, D. V. 1994. Heat stress interaction with shade and cooling. J. Dairy Sci. 77:2044-2050. https://doi.org/10.3168/jds.S0022 -0302(94)77149-6.

Bar, D., L. W. Tauer, G. Bennett, R. N. Gonzalez, J. A. Hertl, Y. H. Schukken, H. F. Schulte, F. L. Welcome, and Y. T. Grohn. 2008. The cost of generic clinical mastitis in dairy cows as estimated by using dynamic programming. J. Dairy Sci. 91:2205-2214. https:// doi.org/10.3168/jds.2007-0573.

Block, J., L. Bonilla, and P. J. Hansen. 2010. Efficacy of in vitro embryo transfer in lactating dairy cows using fresh or vitrified embryos produced in a novel embryo culture medium. J. Dairy Sci. 93:5234-5242. https://doi.org/10.3168/jds.2010-3443.

Brooks, K., G. Burns, and T. E. Spencer. 2014. Conceptus elongation in ruminants: Roles of progesterone, prostaglandin, interferon tau and cortisol. J. Anim. Sci. Biotechnol. 5:53. https://doi.org/10 $.1186 / 2049-1891-5-53$.

Cha, E., D. Bar, J. A. Hertl, L. W. Tauer, G. Bennett, R. N. González, Y. H. Schukken, F. L. Welcome, and Y. T. Gröhn. 2011. The cost and management of different types of clinical mastitis in dairy cows estimated by dynamic programming. J. Dairy Sci. 94:44764487. https://doi.org/10.3168/jds.2010-4123.

Chebel, R. C., J. E. Santos, J. P. Reynolds, R. L. Cerri, S. O. Juchem, and M. Overton. 2004. Factors affecting conception rate after artificial insemination and pregnancy loss in lactating dairy cows. Anim. Reprod. Sci. 84:239-255. https://doi.org/10.1016/j .anireprosci.2003.12.012.

Chung, H. J., K. W. Kim, D. W. Han, H. C. Lee, B. C. Yang, H. K. Chung, M. R. Shim, M. S. Choi, E. B. Jo, Y. M. Jo, M. Y. Oh, S. J. Jo, S. K. Hong, J. K. Park, and W. K. Chang. 2012. Protein profile in corpus luteum during pregnancy in korean native cows. Asian-Australas. J. Anim. Sci. 25:1540-1545. https://doi.org/10 .5713 /ajas.2012.12294

Cullor, J. S. 1990. Mastitis and its influences upon reproductive performance in dairy cattle. Pages $176-180$ in Proc. Int. Symp. Bovine Mastitis, Indianapolis, IN. National Mastitis Council, Madison, WI, and American Association of Bovine Practitioners, Auburn, AL.

Dahl, M. O., F. P. Maunsell, A. De Vries, K. N. Galvão, C. A. Risco, and J. A. Hernandez. 2017. Evidence that mastitis can cause pregnancy loss in dairy cows: A systematic review of observational studies. J. Dairy Sci. 100:8322-8329. https://doi.org/10.3168/jds $.2017-12711$ 
De Vries, A. 2006. Economic value of pregnancy in dairy cattle. J. Dairy Sci. 89:3876-3885. https://doi.org/10.3168/jds.S0022 $-0302(06) 72430-4$

Demetrio, D. G., R. M. Santos, C. G. Demetrio, and J. L. Vasconcelos. 2007. Factors affecting conception rates following artificial insemination or embryo transfer in lactating Holstein cows. J. Dairy Sci. 90:5073-5082. https://doi.org/10.3168/jds.2007-0223.

Gráff, M., S. Pinnyey, and E. Mikó. 2016. The effect of lameness on body condition, milk production and somatic cell count in a Holstein-Friesian farm. Lucrări Științifice, Universitatea De Științe Agricole Și Medicină Veterinară A Banatului, Timisoara, Seria I, Management Agricol 18:103-108. Accessed Sep. 13, 2017. http:// lsma.ro/index.php/lsma/article/view/900.

Hansen, P. J. 2002. Embryonic mortality in cattle from the embryo's perspective. J. Anim. Sci. 80:E33-E44. https://doi.org/10.2527/ animalsci2002.80E-Suppl_2E33x.

Hansen, P. J., P. Soto, and R. P. Natzke. 2004. Mastitis and fertility in cattle - Possible involvement of inflammation or immune activation in embryonic mortality. Am. J. Reprod. Immunol. 51:294-301. https://doi.org/10.1111/j.1600-0897.2004.00160.x.

Hernandez, J. A., C. A. Risco, F. S. Lima, and J. E. Santos. 2012. Observed and expected combined effects of clinical mastitis and low body condition on pregnancy loss in dairy cows. Theriogenology 77:115-121. https://doi.org/10.1016/j.theriogenology.2011.07.023.

Hertl, J. A., Y. H. Schukken, D. Bar, G. J. Bennett, R. N. Gonzalez, B. J. Rauch, F. L. Welcome, L. W. Tauer, and Y. T. Grohn. 2011. The effect of recurrent episodes of clinical mastitis caused by gram-positive and gram-negative bacteria and other organisms on mortality and culling in Holstein dairy cows. J. Dairy Sci. 94:48634877. https://doi.org/10.3168/jds.2010-4000.

Hockett, M. E., F. M. Hopkins, M. J. Lewis, A. M. Saxton, H. H. Dowlen, S. P. Oliver, and F. N. Schrick. 2000. Endocrine profiles of dairy cows following experimentally induced clinical mastitis during early lactation. Anim. Reprod. Sci. 58:241-251. https://doi .org/10.1016/S0378-4320(99)00089-5

Hosmer, D. W., and S. Lemeshow. 2000. Applied Logistic Regression. Wiley Series in Probability and Statistics. 2nd ed. John Wiley and Sons, New York, NY.

Kelly, C. F., and T. E. Bond. 1971. Bioclimatic factors and their measurement. Pages 7-92 in A Guide to Environmental Research on Animals. National Academy of Science, Washington, DC.

Kuritz, S. J., and J. R. Landis. 1987. Attributable risk ratio estimation from matched-pairs case-control data. Am. J. Epidemiol. 125:324-328.

Mayes, M. 2002. The meiotic arrest of bovine oocytes. PhD thesis. Department of Animal Sciences, Faculty of Agricultural Sciences, University of Laval, Quebec, Canada.

Moore, D. A., M. W. Overton, R. C. Chebel, M. L. Truscott, and R. H. Bondurant. 2005. Evaluation of factors that affect embryonic loss in dairy cattle. J. Am. Vet. Med. Assoc. 226:1112-1118. https: //doi.org/10.2460/javma.2005.226.1112.

NAHMS. 2007. Dairy 2007: Part I: Reference of Dairy Health and Management in The United States. USDA, Animal and Plant Health Inspection Service, Veterinary Services, Center for Epidemiology and Animal Health, Fort Collins, CO.

O'Driscoll, K., M. Mccabe, and B. Earley. 2015. Differences in leukocyte profile, gene expression, and metabolite status of dairy cows with or without sole ulcers. J. Dairy Sci. 98:1685-1695. https://doi .org/10.3168/jds.2014-8199.

Pampfer, S. 2001. Dysregulation of the cytokine network in the uterus of the diabetic rat. Am. J. Reprod. Immunol. 45:375-381. https:// doi.org/10.1111/j.8755-8920.2001.450602.x.

Pate, J. L. 1994. Cellular components involved in luteolysis. J. Anim. Sci. 72:1884-1890. https://doi.org/10.2527/1994.7271884x.

Persson Waller, K., I. G. Colditz, S. Lun, and K. Ostensson. 2003. Cytokines in mammary lymph and milk during endotoxin-induced bovine mastitis. Res. Vet. Sci. 74:31-36. https://doi.org/10.1016/ S0034-5288(02)00147-9.
Quist, M. A., S. J. Leblanc, K. J. Hand, D. Lazenby, F. Miglior, and D. F. Kelton. 2007. Agreement of predicted 305-day milk yields relative to actual 305-day milk weight yields. J. Dairy Sci. 90:46844692. https://doi.org/10.3168/jds.2006-833.

Rambeaud, M., R. A. Almeida, G. M. Pighetti, and S. P. Oliver. 2003. Dynamics of leukocytes and cytokines during experimentally induced streptococcus uberis mastitis. Vet. Immunol. Immunopathol. 96:193-205. https://doi.org/10.1016/j.vetimm.2003.08.008.

Risco, C. A., G. A. Donovan, and J. Hernandez. 1999. Clinical mastitis associated with abortion in dairy cows. J. Dairy Sci. 82:1684-1689. https://doi.org/10.3168/jds.S0022-0302(99)75397-X.

Rizos, D., M. Clemente, P. Bermejo-Alvarez, J. De La Fuente, P. Lonergan, and A. Gutierrez-Adan. 2008. Consequences of in vitro culture conditions on embryo development and quality. Reprod. Domest. Anim. 43:44-50. https://doi.org/10.1111/j.1439-0531 2008.01230.x

Santos, J. E., R. S. Bisinotto, E. S. Ribeiro, F. S. Lima, L. F. Greco, C. R. Staples, and W. W. Thatcher. 2010. Applying nutrition and physiology to improve reproduction in dairy cattle. Soc. Reprod. Fertil. Suppl. 67:387-403.

Santos, J. E., W. W. Thatcher, R. C. Chebel, R. L. Cerri, and K. N. Galvão. 2004. The effect of embryonic death rates in cattle on the efficacy of estrus synchronization programs. Anim. Reprod. Sci. 82-83:513-535. https://doi.org/10.1016/j.anireprosci.2004.04.015.

Santos, J. E. P., and E. S. Ribeiro. 2014. Impact of animal health on reproduction of dairy cows. Anim. Reprod. 11:254-269.

Scenna, F. N., M. E. Hockett, T. M. Towns, A. M. Saxton, N. R. Rohrbach, M. E. Wehrman, and F. N. Schrick. 2005. Influence of a prostaglandin synthesis inhibitor administered at embryo transfer on pregnancy rates of recipient cows. Prostaglandins Other Lipid Mediat. 78:38-45. https://doi.org/10.1016/j.prostaglandins.2005 .02 .003 .

Schukken, Y. H., J. Hertl, D. Bar, G. J. Bennett, R. N. Gonzalez, B. J. Rauch, C. Santisteban, H. F. Schulte, L. Tauer, F. L. Welcome, and Y. T. Grohn. 2009. Effects of repeated gram-positive and gram-negative clinical mastitis episodes on milk yield loss in Holstein dairy cows. J. Dairy Sci. 92:3091-3105. https://doi.org/ $10.3168 /$ jds.2008-1557

Shonka, B. N., and D. M. Spurlock. 2014. Impact of lameness on production and intake in Holstein cows. Iowa State University, Animal Industry Report: AS 660, ASL R2883. Accessed Sep. 16, 2017. https://lib.dr.iastate.edu/ans_air/vol660/iss1/48.

Shuster, D. E., M. E. Kehrli Jr., and M. G. Stevens. 1993. Cytokine production during endotoxin-induced mastitis in lactating dairy cows. Am. J. Vet. Res. 54:80-85.

Smith, K. L. 1996. Standards for somatic cells in milk: Physiological and regulatory. Pages 7-9 in International Dairy Federation Mastitis Newsletter. Vol. 21. International Dairy Federation INPA, Brussels, Belgium.

Soto, P., R. P. Natzke, and P. J. Hansen. 2003. Identification of possible mediators of embryonic mortality caused by mastitis: Actions of lipopolysaccharide, prostaglandin f2alpha, and the nitric oxide generator, sodium nitroprusside dihydrate, on oocyte maturation and embryonic development in cattle. Am. J. Reprod. Immunol. 50:263-272. https://doi.org/10.1034/j.1600-0897.2003.00085.x.

Thorup, V. M., B. L. Nielsen, P. E. Robert, S. Giger-Reverdin, J. Konka, C. Michie, and N. C. Friggens. 2016. Lameness affects cow feeding but not rumination behavior as characterized from sensor data. Front. Vet. Sci. 3:37. https://doi.org/10.3389/fvets .2016 .00037

Whay, H. R., A. E. Waterman, A. J. Webster, and J. K. O'Brien. 1998. The influence of lesion type on the duration of hyperalgesia associated with hindlimb lameness in dairy cattle. Vet. J. 156:23-29. https://doi.org/10.1016/S1090-0233(98)80058-0.

Whay, H. R., A. J. Webster, and A. E. Waterman-Pearson. 2005. Role of ketoprofen in the modulation of hyperalgesia associated with lameness in dairy cattle. Vet. Rec. 157:729-733. https://doi.org/ 10.1136/vr.157.23.729. 